\title{
Microstructural Properties of High Level Waste Concentrates and Gels with Raman and Infrared Spectroscopies
}

\author{
EMSP Project FY97 Annual Report
}

Stephen F. Agnew, PI

Robert A. Corbin

Chemical Science and Technology Division

Los Alamos National Laboratory

Los Alamos, NM 87545

Clifford T. Johnston

Dept. of Soil and Agricultural Sciences

Purdue University

Lafayette, IN

\section{Highlights}

- Monosodium aluminate, the phase of aluminate found in waste tanks, is only stable over a fairly narrow range of water vapor pressure (22\% relative humidity at $22 \mathrm{C}$ ). As a result, aluminate solids are stable at Hanford (seasonal average RH $~ 20 \%$ ) but are not be stable at Savannah River (seasonal average RH $40 \%$ ).

- Monosodium aluminate (MSA) releases water upon precipitation from solution. In contrast, trisodium aluminate (TSA) consumes water upon precipitation. As a result, MSA precipitates gradually over time while TSA undergoes rapid accelerated precipitation, often gelling its solution.

- Raman spectra reported for first time for monosodium and trisodium aluminate solids.

- Ternary phase diagrams can be useful for showing effects of water removal, even with concentrated waste.

- Kinetics of monosodium aluminate precipitation are extremely slow (several months) at room temperature but quite fast (several hours) at $60^{\circ} \mathrm{C}$. As a result, all waste simulants that contain aluminate need several days of "cooking" at $60^{\circ} \mathrm{C}$ in order to truly represent the equilibrium state of aluminate.

\section{Introduction}

The high level waste (HLW) slurries that have been created at the Hanford and Savannah River Sites over that last fifty years constitute a large fraction of the remaining HLW volumes at both sites. In spite of the preponderance of these wastes, very little quantitative information is available about their physical and chemical properties other than elemental analyses. 
In particular, the role of aluminate in the rheology and chemistry of waste slurries has been critical but often not well understood. Many waste slurries at Hanford were defined by the fact that they were just on the edge of sodium aluminate precipitation. Now that we transition from waste storage to waste treatment, the dissolution of aluminum oxyhydroxides becomes necessary to minimize the volume of HLW glass.

\section{Experimental}

Aluminate solutions were prepared by A) dissolution of aluminum wire in $\mathrm{NaOH}$ solution as well as by B) dissolution of commercial grade sodium aluminate. The dissolution of aluminum wire mimics the aluminum cladding dissolution that is the primary source of aluminate in high level waste. Care was taken to minimize exposure of the samples to air since aluminate solutions and solids are extremely hygroscopic and deliquescent. In addition, absorption of atmospheric $\mathrm{CO} 2$ occurs readily in solutions exposed to air and therefore such exposure was minimized. Solutions prepared from commercial grade sodium aluminate (method B) were contaminated with carbonate as well as fluorescent impurities that interfered with measurement of Raman spectra. Therefore, most samples were prepared by method A.

Infrared absorption spectra were measured with samples on $\mathrm{ZnSe}$ windows inside of a chamber isolated by $\mathrm{KBr}$ windows from the vacuum of FTIR bench. A DGTS detector was used along with a $\mathrm{Ge} / \mathrm{KBr}$ beamsplitter and globar source in a Bruker 113v FTIR spectrometer. Normally 256 scans were coadded at $4 \mathrm{~cm}-1$ resolution to produce each spectrum.

Raman spectra were recorded with an ISA/JY Ramanor U1000 double scanning one meter spectrometer, with holographic gratings ruled at $1200 \mathrm{~g} / \mathrm{mm}$. Samples were excited with an $\mathrm{Ar}$ ion laser at $488 \mathrm{~nm}$ with around $500 \mathrm{~mW}$ power at the sample. A Spex grating filter monochromater was used to remove plasma lines from the laser excitation.

\section{Results}

Shown in Fig. 1 is a ternary phase diagram for the components A12O3/Na2O/H2O. This representation of the phase diagram is quite useful for discussing concentration effects in caustic solutions containing aluminate. Note that since high level waste also contains other components such as nitrate and nitrite ions, the pure aluminum/sodium/water representation can be used as a slice of a larger dimensional space representing components likely to precipitate. 


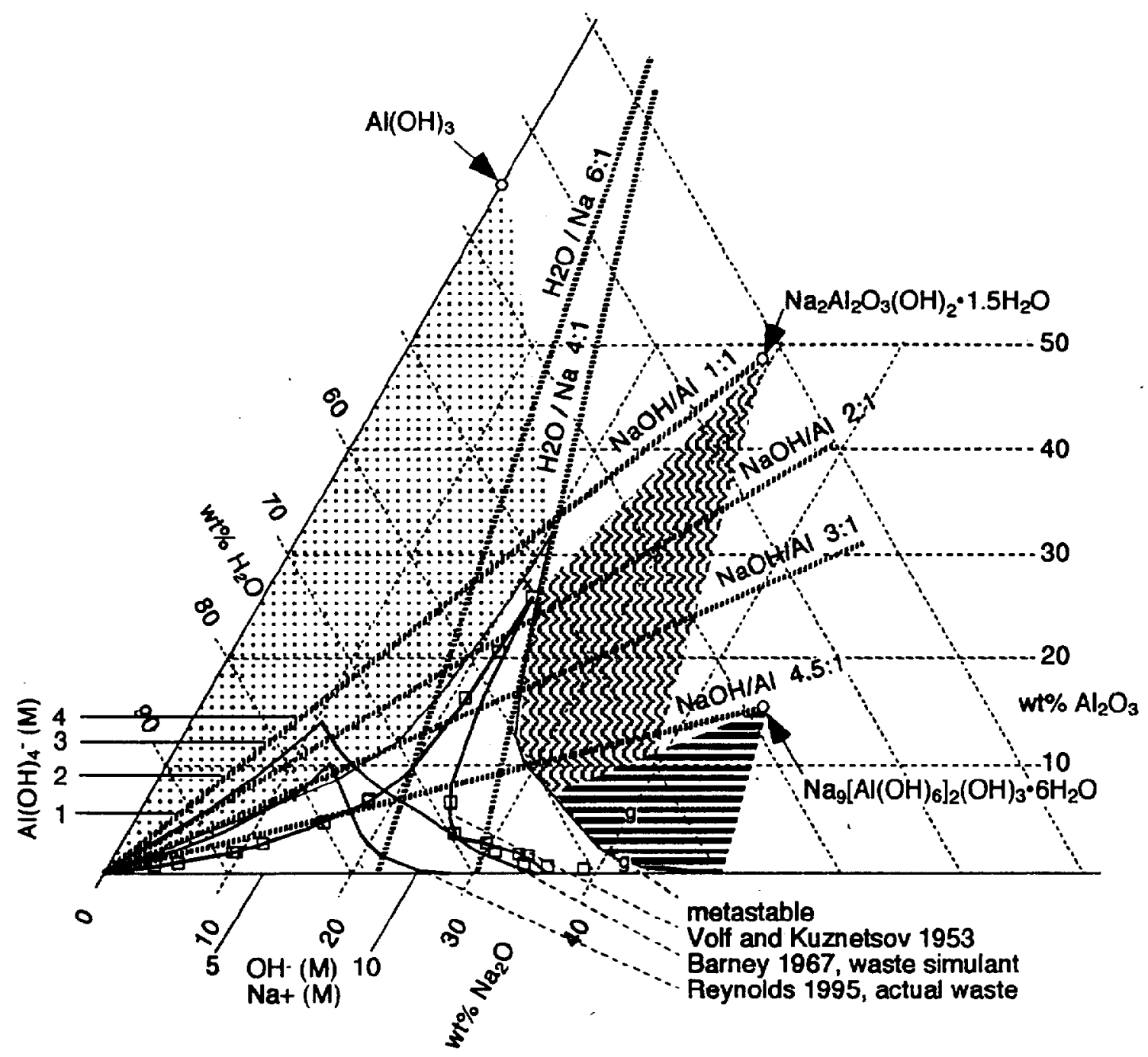

Fig. 1. Ternary phase diagram for the system A12O3/Na2O/H2O.

Any change of a single component of this three component mixture, such as loss of water by evaporation, can be represented as a straight line trajectory on the ternary diagram intersecting the $100 \%$ water vertex. Four such trajectories are shown with differing $\mathrm{NaOH}$ to $\mathrm{Al}$ mol ratios. With $\mathrm{NaOH}: \mathrm{Al}$ of $1: 1$, the trajectory lies in the gibbsite stability regime until water contents drop below $45 \mathrm{wt} \%$ or so. At this point, the endpoint becomes the monosodium aluminate, often referred to as the 1.25 hydrate. In other words, aluminate ion is not stable in solution unless there is excess $\mathrm{NaOH}$ present. Otherwise, $\mathrm{Al}(\mathrm{OH}) 3$ precipitates until the solution moves into the unsaturated regime shown on the diagram.

When $\mathrm{NaOH} / \mathrm{Al}$ mol ratio is 2:1, the trajectory passes through the gibbsite regime and emerges at about $58 \mathrm{wt} \%$ water. Once again above this water content, the gibbsite phase will precipitate. With a $\mathrm{NaOH} / \mathrm{Al}$ ratio of $3: 1$, a water content of $65 \mathrm{wt} \%$ will stabilize the solutions against precipitation of gibbsite. Thus, without sufficient excess of hydroxide, aluminate solutions will not be stable and will precipitate gibbsite. 
On the other hand, there is a very narrow range for solution stability before MSA precipitates as shown in Fig. 1. In this range of aluminate, hydroxide, sodium, and water, the solutions are only metastable or exist unsaturated over very narrow ranges of composition. Superposed on the ternary diagram are actual waste compositions without regard to other components. This mapping is quite useful to demonstrate that the unsaturated aluminate stability regime shifts in particular ways with the addition of other components. However, note that if one considers the total sodium content of actual waste $(\sim 10 \mathrm{M} \mathrm{Na})$ as opposed to its hydroxide alone, the curve shown for "actual waste" in Fig. 1 would shift to the right until its peak was aligned on the $10 \mathrm{M} \mathrm{Na}$ diagonal. In other words, the reported unsaturated regime for actual waste would be very close to that shown for the pure three component system.

Recently, work by Gessner and coworkers as well as Kaduk and Pei have reported the crystal structures of the monosodium and trisodium phases of aluminate $\left(\mathrm{Na}_{2}\left[\mathrm{AlO}_{3}(\mathrm{OH})_{2}\right] \cdot 1.5 \mathrm{H}_{2} \mathrm{O}\right.$ is $\mathrm{MSA}$ and $\mathrm{Na}_{6}\left[\mathrm{Al}(\mathrm{OH})_{6}\right]_{2}[\mathrm{NaOH}]_{3}{ }_{6} \mathrm{H}_{2} \mathrm{O}$ is TSA). In light of this work, it is now clear that monosodium aluminate is actually a 0.75 hydrate per aluminum, with the other 0.75 water bound up as hydroxide to the aluminate planes. This phase consists of aluminum tetrahedra bonded in a plane with one hydroxide per aluminum sticking out of the plane. Aluminum tetrahedra are coupled into four and eight membered rings of polyhedra with the eight-membered rings forming vertical channels from plane to plane. The sodium ions and waters of hydration are all contained within these linear channels.

This structure stands in sharp contrast to that of potassium aluminate. Potassium aluminate is formed of discrete dimers of aluminate ions [Johansson, 1966] and not planer polymers at all.

The trisodium aluminate is an octahedrally coordinated aluminum hydroxide ion whose trisodium salt forms as a cocrystal with 1.5 equivalents of $\mathrm{NaOH}$. It consists of 1.5 equivalents of $\mathrm{NaOH}$ as well as 3 equivalents of water per $\mathrm{Al}(\mathrm{OH})_{6}{ }^{3 \cdot}$ unit.

\section{Kinetics of aluminate precipitation:}

Precipitation of sodium aluminate from supersaturated solutions is extremely slow at room temperature $(22 \mathrm{C})$. In fact, very concentrated solutions $(5-6 \mathrm{M} \mathrm{Al})$ can be prepared as long as they are not heated above about $40 \mathrm{C}$. At $60 \mathrm{C}$, all supersaturated' solutions precipitated monosodium aluminate over a period of hours to days. At $22 \mathrm{C}$, these solutions were stable for several months.

It is very important that the kinetics of aluminate crystallization be allowed for in making aluminate slurries that desire to represent properties of HLW. Without an adequate cooking time, we find that the aluminate does not precipitate in solution even over a period of several months.

Water vapor pressure for aluminate slurries: 
We have measured the water vapor pressure of aluminate solutions in equilibrium with the mono sodium and trisodium aluminate. Both of these solids show ready deliquescence when exposed to water vapor in excess of the equilibrium water vapor pressures. The MSA has a relative humidity of $22 \%$ at $22 \mathrm{C}$ while that of the trisodium is $11 \%$.

Supersaturated solutions of aluminate can be readily prepared with RH between 11 and $22 \%$. These metastable solutions all shift to $22 \% \mathrm{RH}$ after MSA precipitates. Water activity seems to be the determining factor in establishing the solubility limits of both MSA and TSA .

Seasonal average water vapor pressure for the Hanford Site are about 5.1 torr, which is about $20 \% \mathrm{RH}$ at $22 \mathrm{C}$. Variation of relative humidity from winter to summer shows that $\mathrm{RH}$ ranges from 3 to 9 torr for the year. Thus, any waste tank with MSA that is exposed to the dome headspace will necessarily have a vapor pressure very close to that of MSA The solution that is in contact with MSA will likewise-be "buffered" to this same water activity. Increasing water content will shift aluminate into solution whereas decreasing water content will simply precipitate more aluminate. The water vapor pressure of MSA slurries will not change until all aluminate is precipitated from solution.

Seasonal average RH for Savannah River are on the order of $40 \%$ or so. Thus, MSA is inherently unstable and cannot be produced in such a humid environment. In fact, the highly concentrated aluminate slurries that have been produced in abundance at Hanford were never stable at Savannah River.

\section{Raman spectra:}

Raman spectra of aluminate solution, MSA, and TSA in the 200-800 cm-l region are shown in Fig. 2. Peak positions for various features are shown in Table 1 with preliminary assignments. Note the single peaks for both $\mathrm{Al}(\mathrm{OH}) 4-$ and $\mathrm{Al}(\mathrm{OH}) 63$ - species represent the shift in Al-OH stretch from 622 to $500 \mathrm{~cm}-1$ upon going from tetrahedral to octahedral coordination.

In contrast, we find the AI-OH stretch of MSA to have increased to $661 \mathrm{~cm}-1$. An Al-O$\mathrm{Al}$ backbone feature appears now at $443 \mathrm{~cm}-1$, shifted from the Al-O-Al feature of the dimer at $700 \mathrm{~cm}-\mathrm{l}$. This is consistent with the nature of the extreme hydrogen bonding present in MSA (see below). 


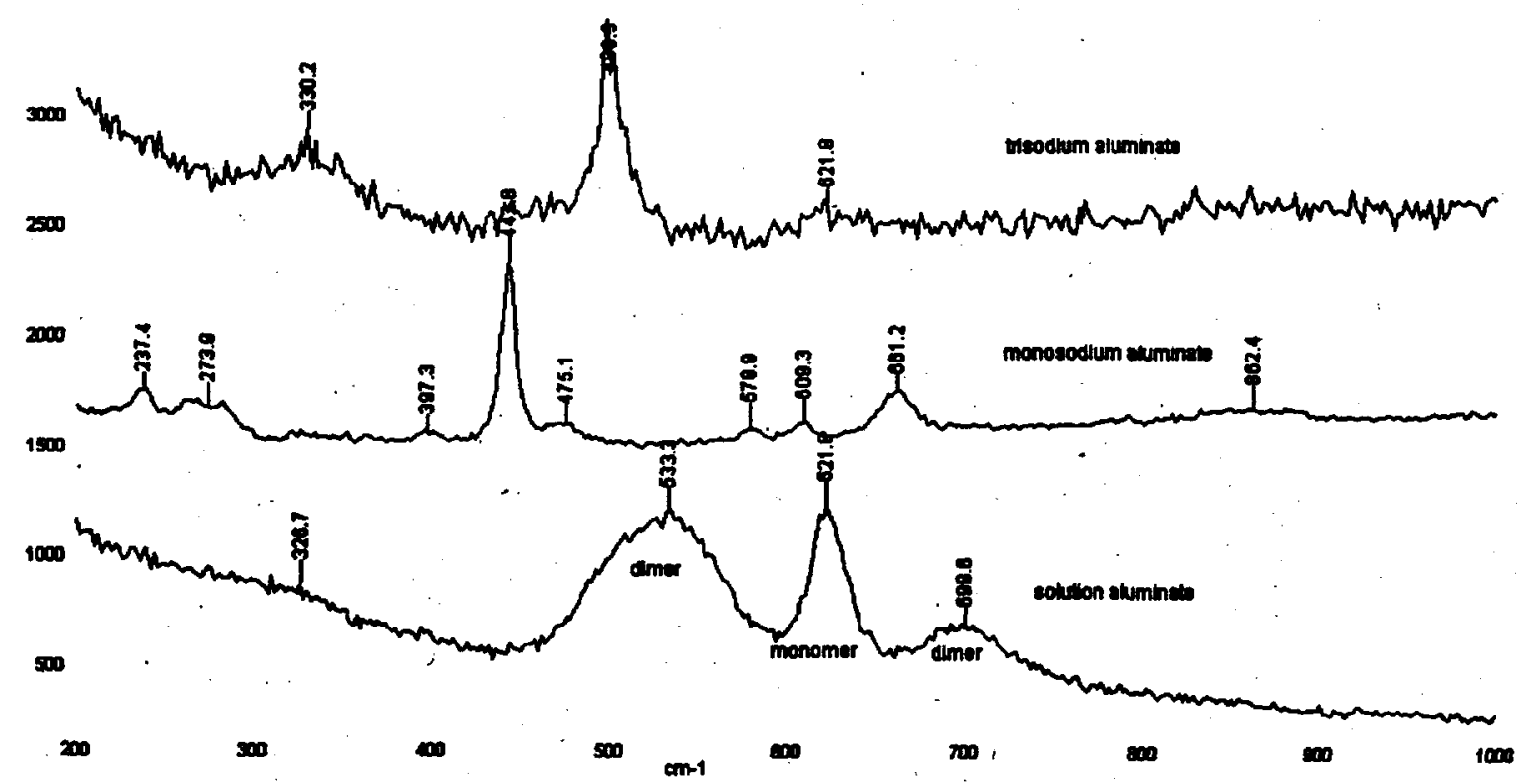

Fig. 2. Raman spectra of aluminate for phases as shown

In Fig. 3 we show the high frequency region for the aluminum phases, with band positions as shown in Table 2. For aluminate solutions, there are two primary hydroxl features, one associated with waterlike $\mathrm{O}-\mathrm{H}$ at $3394 \mathrm{~cm}-1$ and the other with $\mathrm{O}-\mathrm{H}$ of hydroxide at 3605 $\mathrm{cm}-\mathrm{l}$. The hydroxide feature of the MSA shifts to lower frequency and splits into two components, 3543 and $3563 \mathrm{~cm}-1$, while the waterlike feature shifts to much lower frequency. This suggests an increasing hydrogen bond for this hydroxide in MSA. The two lower frequency features appearing at 2800 and $3100 \mathrm{~cm}-1$ are evidently associated with bound water that is involved in this hydrogen bond. 


\begin{tabular}{|c|c|c|}
\hline species & $\begin{array}{l}\text { peak } \\
\text { cm }^{-1} \\
\end{array}$ & tentative assignment \\
\hline $\begin{array}{l}\text { monomer } \\
\mathrm{Al}\left(\mathrm{OH}_{4}^{-}\right.\end{array}$ & 622 & Al-OH sym.str. \\
\hline $\begin{array}{c}\text { dimer } \\
\mathbf{A l}_{2} \mathbf{O}(\mathrm{OH})_{6}{ }^{2-}\end{array}$ & $\begin{array}{l}533 \\
700\end{array}$ & $\begin{array}{l}\text { Al-OH sym. str. } \\
\text { Al-O str. }\end{array}$ \\
\hline $\begin{array}{c}\mathrm{MSA} \\
\mathrm{Na}_{2}\left[\mathrm{Al}_{2} \mathrm{O}_{3}(\mathrm{OH})_{2}\right] \bullet \\
1.5 \mathrm{H}_{2} \mathrm{O}\end{array}$ & $\begin{array}{l}327 \\
443 \\
661 \\
\end{array}$ & $\begin{array}{c}\text { Al-O str. } \\
\text { Al-OH sym.str. }\end{array}$ \\
\hline $\begin{array}{c}\mathrm{TSA} \\
\mathrm{Na}\left[\mathrm{A}(\mathrm{OH})_{6}\right]_{2} \\
{[\mathrm{NaOH}]_{\mathbf{3}} \cdot \mathbf{3} \mathbf{H}_{2} \mathrm{O}}\end{array}$ & $\begin{array}{l}330 \\
499 \\
622\end{array}$ & $\begin{array}{l}\text { Al-OH sym.str. } \\
\text { solution } \mathrm{Al}(\mathrm{OH})_{4}\end{array}$ \\
\hline
\end{tabular}

In contrast to the MSA, the O-H stretching features for TSA shift to higher frequency as shown in Fig. 3, and the most prominent band appears at $3623 \mathrm{~cm}-1$. This suggests that the hydroxide is less strongly hydrogen bonded in the TSA than either solution or MSA phases. Consistent with this is the fact that the waterlike feature is basically still at around $3300 \mathrm{~cm}-1$.

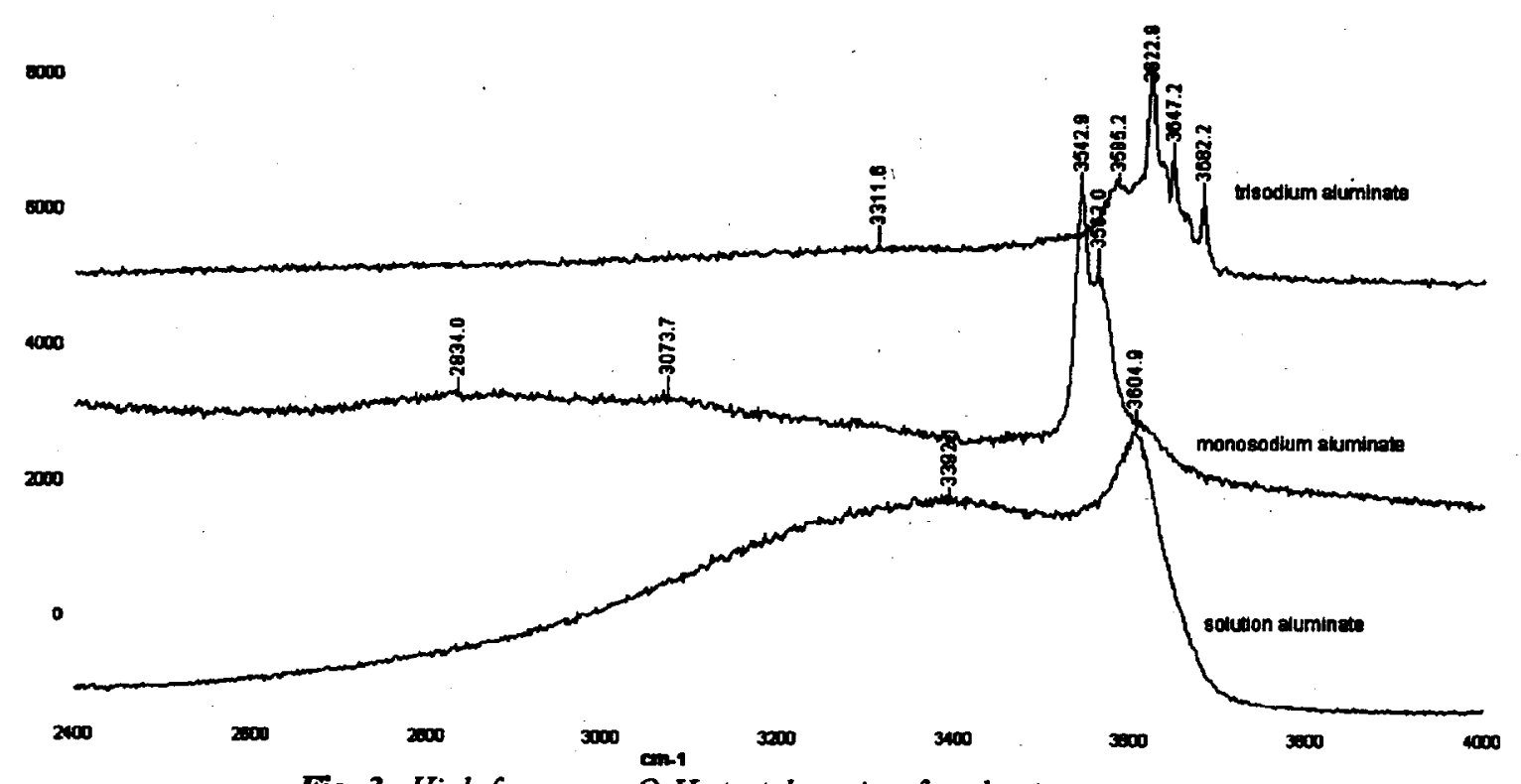

Fig. 3. High frequency $O-H$ stretch region for aluminate species. 


\begin{tabular}{|c|c|c|}
\hline species & $\begin{array}{l}\text { peak } \\
\mathrm{cm}^{-1}\end{array}$ & tentative assignment \\
\hline $\mathrm{Al}(\mathrm{OH})_{4}$ and $\mathrm{Al}_{2} \mathrm{O}(\mathrm{OH})_{6}^{2-}$ & $\begin{array}{l}3392 \\
3605 \\
\end{array}$ & $\begin{array}{l}\text { water } \mathrm{O}-\mathrm{H} . . . \mathrm{O} \text { str. } \\
\mathrm{O}-\mathrm{H} \text { str. } \mathrm{OH}\end{array}$ \\
\hline $\begin{array}{l}\text { MSA } \\
\mathrm{Na}_{2}\left[\mathrm{Al}_{2} \mathrm{O}_{3}(\mathrm{OH})_{2}\right] \cdot 1.5 \mathrm{H}_{2} \mathrm{O}\end{array}$ & $\begin{array}{l}2834 \\
3074 \\
3543 \\
3562 \\
\end{array}$ & $\begin{array}{l}\text { water O-H...O str. } \\
\text { water O-H...O str. } \\
\text { O-H str. AlOH } \\
\text { O-H str. AlOH } \\
\end{array}$ \\
\hline $\begin{array}{l}\text { TSA } \\
\mathrm{Na}_{6}\left[\mathrm{Al}(\mathrm{OH})_{6}\right]_{2}[\mathrm{NaOH}]_{3} \cdot 3 \mathrm{H}_{2} \mathrm{O}\end{array}$ & $\begin{array}{l}3312 \\
3585 \\
3623 \\
3647 \\
3682\end{array}$ & $\begin{array}{l}\text { water } \mathrm{O}-\mathrm{H} . . . \mathrm{O} \text { str. } \\
\mathrm{O}-\mathrm{H} \text { str. } \mathrm{NaOH} \\
\mathrm{O}-\mathrm{H} \text { str. } \mathrm{Al}(\mathrm{OH})_{6}{ }^{3-} \\
\mathrm{O}-\mathrm{H} \text { str. } \mathrm{Al}(\mathrm{OH})_{6}{ }^{3-} \\
\mathrm{O}-\mathrm{H} \text { str. } \mathrm{Al}(\mathrm{OH})_{6}{ }^{3-}\end{array}$ \\
\hline
\end{tabular}

Infrared absorption of aluminate solution:

Fig. 4 shows a comparison between the infrared absorption and Raman scattering of the aluminate solutions. In both spectra, aluminate concentrations are on the order of $5 \mathrm{M}$. However, the sample used for the infrared is contaminated with carbonate as indicated by the features at 1265 and $1332 \mathrm{~cm}^{-1}$. Whereas the $\mathrm{O}-\mathrm{H}$ of hydroxide is very prominent in Raman, it is only a shoulder in the infrared absorption.

The feature at $1660 \mathrm{~cm}^{-1}$ corresponds to a deformation mode of water. This feature is then very representative of molecular water and a much more sensitive indication of the state of the water molecule than is the $\mathrm{O}-\mathrm{H}$ absorption at $3400 \mathrm{~cm}^{-1}$.

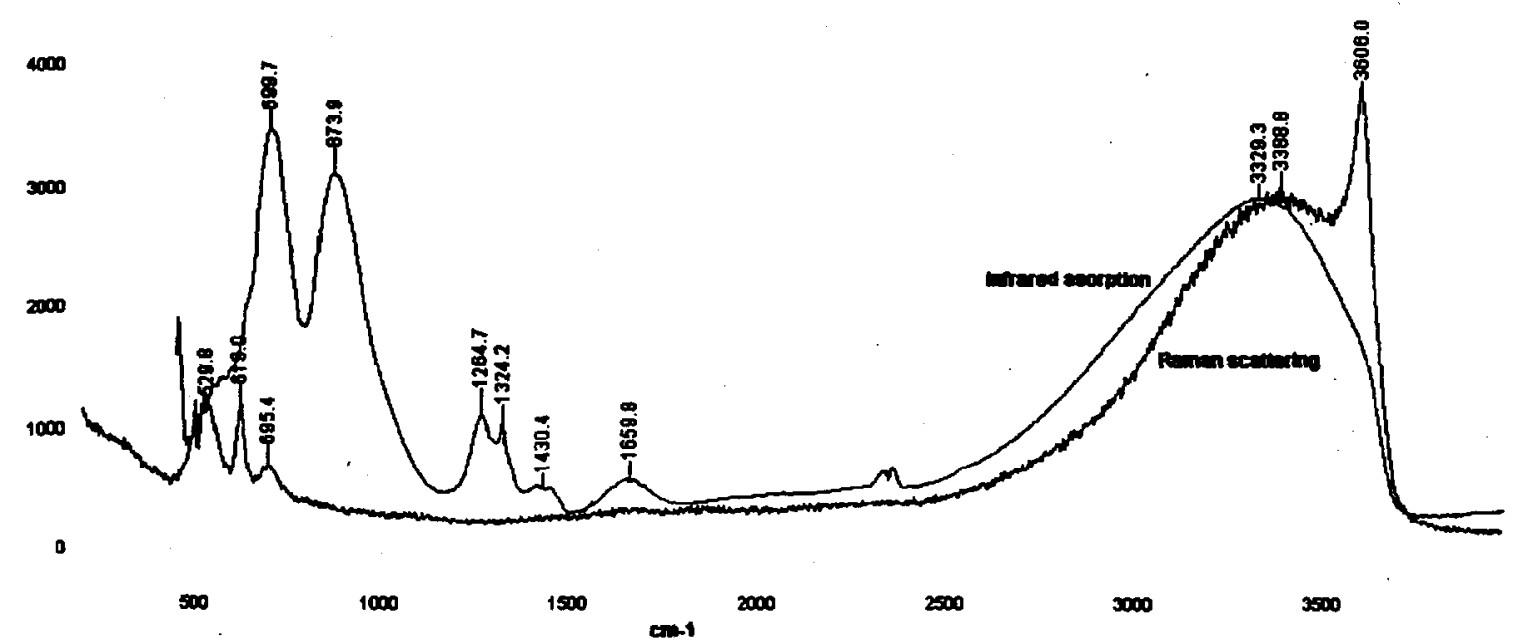

Fig. 4. Infrared absorption and Raman scattering for aluminate solutions.

Al-27 NMR:

Table 3 shows the results of Al-27 NMR for various solutions. Very little change 
occurred in the position of the absorption around $80 \mathrm{ppm}$, but substantial increases in the linewidth occurred with an increase in $\mathrm{Al}$ from 2.1 to $7.7 \mathrm{M}$. Moolenaar et al. suggested that the lower symmetry of the dimer would preclude its observation altogether because of dielectric broadening at the Al-27 nuclei. The increase in linewidths with increasing aluminate is evidently a reflection of the increasing viscosity of these solutions.

\section{Table 3. Al-27 NMR results for various solutions.}

\begin{tabular}{l|l|l|l|l|l|l}
\hline AIM & OH-M & H2OM & Na M & NO2-M & \%dimer & Al-27 ppm \\
\hline 2.1 & 2.3 & 52 & 4.4 & 0 & $<\%$ & $80.1(0.8)$ \\
\hline 4.4 & 2.5 & 51 & 6.9 & 0 & $-18 \%$ & $80.2(3.1)$ \\
\hline 7.7 & 3.0 & 49 & 11 & 0 & $-40 \%$ & $80.7(6.9)$ \\
\hline & & & & & & \\
\hline 6.6 & 2.6 & 42 & 14 & 4.4 & $-40 \%$ & \\
\hline
\end{tabular}

\section{Discussion}

Nature of aluminate in solution:

The position of the hydroxide $\mathrm{O}-\mathrm{H}$ absorption in the infrared has long been associated with the strength of its hydrogen bond to other species. A completely "free" O-H stretch, i.e. one that has no hydrogen bond at all, is normally considered to be about $3750 \mathrm{~cm}-1$ [ref]. In solution, the hydroxide band at $3605 \mathrm{~cm}-1$ is associated not only with hydroxide bound to $\mathrm{Al}(\mathrm{OH}) 4$-, but also to excess $\mathrm{NaOH}$ in solution.

The low frequency region shows bands associated with the dimer of aluminate. This has been assigned by Moolenaar, et al. on the basis of comparison with the potassium salt, which is composed of discrete dimers as $\mathbf{K}_{2}\left[\mathrm{Al}_{2} \mathrm{O}(\mathrm{OH})_{6}\right]$. However, the superficial resemblance of the two low frequency bands in both MSA and TSA (see Fig. I), which do not have any dimer, suggests that this argument may not be valid. However, concentration dependence of the "dimer" bands does support their assignment as the dimer.

Monosodium aluminate 0.75 hydrate:

The extremely low frequency for the $\mathrm{OH}$ stretch for MSA $\left(3543 \mathrm{~cm}^{-1}\right)$ suggests that there is a very strong hydrogen bonding environment for this hydroxide. The waters of hydration for MSA then appear to be much different from that for solution or for TSA. Note the extremely low frequencies for $\mathrm{O}-\mathrm{H}$ absorption for the waters of hydration. These waters of hydration show extreme perturbation also consistent with an large hydrogen bonding effect. Formation of MSA from solution $\mathrm{Al}(\mathrm{OH})_{4}$ releases 0.75 equivalents of free water per aluminum. Thus, even though 0.75 equivalents of water are held in the crystal as waters of hydration, another 0.75 equivalents are released to the solution by MSA precipitation.

$$
\mathrm{Al}(\mathrm{OH})_{4}^{-} \text {(solution) } \rightarrow 1 / 2 \mathrm{Al}_{2} \mathrm{O}_{3}\left(\mathrm{OH}_{2}{ }^{2-} \text { (solid) }+0.75 \mathrm{H}_{2} \mathrm{O} \text { (free) }+0.75 \mathrm{H}_{2} \mathrm{O}\right. \text { (hydration) }
$$

This behavior by MSA actually suppresses further crystal growth from solution since the activity of the solution water rises as MSA precipitates. Thus; MSA growth can only 
occur from supersaturated solutions-as soon as the water activity of the solution increases to the appropriate point (i.e. $22 \% \mathrm{RH}$ at $22 \mathrm{C}$ ), all crystal growth ceases.

We have found that once formed, the monosodium phase is very much like a clay mineral in its gelling characteristics. That is, it demonstrates a reversible shear thinning (thixotropy) very similar to that associated with clay minerals. One of the intriguing aspects of MSA has been its tendency to form highly monodisperse slurries in various simulants. We believe this, property is linked to the changes in water activity that occur upon precipitation. Thus, aluminate solids are strongly associated with changes in water content of the, solution with which they are in contact. In particular, MSA solids in equilibrium with solution aluminate act as a constant humidity source. This explains why there aluminate slurries are virtually unknown at Savannah River while they are extremely common at Hanford.

\section{Trisodium aluminate 1.5 sodium hydroxide 1.5 hydrate:}

The O-H absorption of TSA most closely approximates that of a free hydroxyl. Note that the trisodium phases is actually a cocrystal with $\mathrm{NaOH}$ and therefore shows $\mathrm{O}-\mathrm{H}$ absorption at $-3600 \mathrm{~cm}^{-1}$ that we normally associate with this type of hydroxide. In contrast to MSA, TSA consumes 3 equivalents of water for each $\mathbf{A}(\mathbf{O O H})_{6}{ }^{3-}$ moiety. Thus, precipitation of TSA leads to a cascade effect whereby water activity is lowered, thereby inducing more precipitation.,

\section{Al(OH) $)_{4}^{-}$(solution) $+2 \mathrm{OH}^{-}+3 \mathrm{H}_{2} \mathrm{O}$ (free) $\rightarrow$ Al(OH) $)_{6}{ }^{3-}$ (solid) $+3 \mathrm{H}_{2} \mathrm{O}$ (hydration)}

Upon reaching the point of crystallization, TSA solutions tend to undergo accelerated solidification that is caused by the consumption of three equivalents of water for each. aluminum. Thus, the remaining solution is further concentrated by TSA precipitation, which then leads to more TSA formation. Since water activity is already very low for TSA slurries (around 11\% RH at 22 C), it is not unusual for the entire solution to suddenly gel or solidify.

\section{Conclusion}

The very slow kinetics for monosodium aluminate precipitation at room temperature, even with large aluminate concentrations, means that waste simulants with aluminate need to be prepared very carefully if one expects those simulants to represent characteristics of waste in the tanks. In particular, heating waste simulants at $60^{\circ} \mathrm{C}$ for several days is needed to allow the monosodium phase to precipitate and equilibrate with the solution.

Monosodium aluminate is only stable at relative humidity on the order of $22 \%$. Below this value,. the solid dehydrates to an as yet undetermined form while about this humidity, the solid readily deliquesces (absorbs water), there by dissolving.

When exposed to water vapor above $22 \% \mathrm{RH}$, MSA completely dissolves and eventually precipitates gibbsite, $\mathrm{Al}(\mathrm{OH}) 3$. If an aluminate slurry is prepared, the $\mathrm{RH}$ of that slurry is fixed at $22 \%$ as long as there are aluminate as both MSA and in solution. 
The hydrogen bonding of the MSA phase is much stronger than that in clay minerals as well as for aluminate solutionsand other aluminate phases. The waters of hydration in aluminate show correspondingly larger perturbations of their frequency positions as well.

\section{Future Work}

We need to complete our survey of the infrared absorption of these materials. We have found that these slurries are compatible with $\mathrm{ZnSe}$ windows and infrared absorption can be readily measured in thin layers. The water deformation mode at $1650 \mathrm{~cm}^{-1}$ is very sensitive to the environment of the water. We have found that this band shows distinct differences between free water and that bound as a hydrate. Moreover, the combination mode at $\sim 2400 \mathrm{~cm}^{-1}$ is also very sensitive to the nature of the water. This is presumably: due to the more highly defined libration associated with water bound as a hydrate.'

We began our work with incorporating other components with the aluminate, in particular $\mathrm{NaNO}_{2}$ but found that we didn't even understand the complexity of the aluminate all by itself. Now that we have a better grasp on aluminate behavior, we plan to return to these mixtures and explore the changes in aluminate speciation when other components are present. The ternary phase diagram can be used to represent the stability regimes of aluminum oxides "even in more complex mixtures. This requires a "sodium scaling" as opposed to a hydroxide scaling. We will be exploring this relationship in much more detail.

\section{Meetings:}

"IR and Raman Studies of High Level Waste Concentrates," 52nd Northwest Regional American Chemical Society Meeting, Crosby Symposia, Moscow, ID; June 18-21, 1997.

\section{Publications:}

in preparation.

\section{Summer Faculty support:}

Prof. Cliff Johnston, Purdue Univ.

\section{Post Doe Support:}

Curtis Westerfield, now at Komag, Inc.

\section{Literature Cited:}

Weinberger, M; Schneider, M., Miller, D.; Gessner, W. "The Crystal Structure of the Sodium Oxohydroxoaluminate Hydrate," Z. anorg. allg. Chem. 621, 679-84 (1995). In german with english abstract.

The following workers at Amoco actually did a powder structure refinement with the Brookhaven Synchrotron Source. Their structure is virtually identical with Gessner's single crystal work. Plus, they did the dehydrated aluminate structure as well.

Kaduk, J.A.; Pei, S. "The Crystal Structure of the Hydrated Sodium Aluminate, NaA1O2*5/4H2O, and Its Dehydration Product," J. Solid State Chem. 115, 126-39 (1995).

More work by Gessner on the so-called "trisodium" aluminate. This stoichiometry is actually

$\mathrm{Na9}[\mathrm{Al}(\mathrm{OH}) 6] 2(\mathrm{OH}) 3 * 6 \mathrm{H} 20$, i.e. 4.5 sodiums per aluminum, not three, and octahedrally coordinated 
aluminum. Gessner argues that previous assignments of this aluminate to "trisodium" were complicated by the presence of mother liquor, other aluminate phases, and impurities. Note that if you take away 1.5 equivalents of $\mathrm{NaOH}$, you do indeed end up with three Na's per Al.

Zabel, V.; Schneider, M; Weinberger, M; Gessner, W. "Nonasodium Bis(hexahydoxoaluminate) Trihydroxide Hexahydrate," Acta Cryst. C52, 747-9 (19\%). In English.

Nonasodium Bis(hexahydroxoaluminate) Trihydroxide Hexahydrate (Na9[A](OH)6]2(OH)3*6H2OCrystal Structure, NMR Spectroscopy and Thermal Behavior,” Z. anorg. allg. Chemie 622, 1799-305 (1996). In german with english abstract.

Most of Gessner's arguments about the octahedral aluminate actually appear some years earlier: Gessner, W.; Weinberger, M; Mueller, D. "On the Crystalline Phases of the Systems M2O-A12O3-H20 $(\mathrm{M}=\mathrm{K}, \mathrm{Na})$, “Z. anorg. allg. Chem. 547, 27-44 (1987). In german with english abstract.

Barney, G. S. "Vapor-Liquid-Solid Phase Equilibria of Radioactive Sodium Salt Wastes at Hanford," ARH-ST-133, Atlantic Richfield Hanford Company, Richland, WA 1976.

Reynolds, D. A and D. L. Herting, "Solubilities of Sodium Nitrate, Sodium Nitrite, and Sodium Aluminate in Simulated Nuclear Waste", Rockwell Hanford Operations, RHO-RE-ST-14P, 1984.

Everett, D. "Basic Principles of Colloid Science," Royal Society of Chemistry, London, 1988.

Reynolds, D. A and L. Herting, "Solubilities of Sodium Nitrate, Sodium Nitrite, and Sodium

Aluminate in Simulated Nuclear Waste", Rockwell Hanford Operations, RHO-RE-ST-14P, 1984.

Wesolowski, D. J., "Aluminum speciation and equilibria in aqueous solution: I. The solubility of gibbsite in the system $\mathbf{N a -} \mathbf{K}-\mathbf{C l}-\mathbf{O H}-\mathbf{A l}(\mathbf{O H})_{4}$ from 0 to $100^{\circ} \mathrm{C}$ ”, Geochimical et Cosmochimica Acta, 1991, 56, 1065 .

Reynolds, D. A., "Practical Modeling of Aluminum Species in High-pH Wastes"; Westinghouse Hanford Company, WHC-EP-0872, October, 1995.

Moolenaar, R J., J. C. Evans, and L. D. McKeever, The Structure of the Aluminate Ion in Solution at High pH", J. Phys. Chem., 1970, 74, 3629.

Johansson G., The Crystal Structure of Potassium Aluminate", Acta Chem. Scand., 1966, $20,505$.

Sxita, L. and E. Berecz, "The Structure of Sodium Aluminate Liquors I.," Magy. Kem. Polyoirat., 1975a, $81,383$.

Sxita, L. and E. Berecz, The Struck of Sodium Aluminate Liquors II.," Magy. Kem. Polyoirat., 1975b, $81,386$.

R T. Allemann, "Some Theories of Dissolved Gas Release from Tank 241:SY-101", Pacific Northwest Laboratories, PNL-10091, September 1994.

Agnew, S. F., "Hanford Defined Wastes: Chemical and Radionuclide Compositions," Los Alamos National Laboratory, LAUR-94-2657 Rev. 2, September 1995.

Westerfield, C. and S. A Agnew, "Infrared Study of the Chemistry of Boundary Lubrication with High Temperature and High Pressure Shear, Wear, 181-183, 805 (1995). 
Volf, F. F.; Kuznetsov, S. I. "Polytherms in the A12O3-Na2O- $\mathbf{H 2 O}$ System" J. Appl. Chem. USSR (Engl. Transl.) 1955, 28, 565-9.

Panasko, G.A; Yashunin, P.V. "Calculations for the Na2O-A1203-H2O System" J. Appl. Chem. USSR (Engl. Transl.) 1964, 37, 298-301.

Raizman, V.L.; Puchkov, L.V.; Pevzner, 1.2.; Nesikhin, M.M. "Thermodynamic Estimation of the Constitution of singly charged Aluminum-Bearing rolls in Aluminate Solutions in the Aluminum Hydroxide-Sodium Hydroxide-Water System" J. Gen. Chem. USSR (Engl. Transl.) 1981, 51, 809-14.

Eremin, N.I; Volokhov, Y.A; Mironov, V.E. "Structure and Behaviour of Aluminate Ions in Solution" Russian Chemical Reviews (Engl. Transl.) 1974, 43, 92-106. 